\title{
Retaining perivascular tissue of human saphenous vein grafts protects against surgical and distension-induced damage and preserves endothelial nitric oxide synthase and nitric oxide synthase activity
}

Michael R. Dashwood, PhD, ${ }^{\text {a }}$ Kay Savage, PhD, ${ }^{\text {a }}$ Janice C. S. Tsui, MD, FRCS, ${ }^{\text {a }}$ Audrey Dooley, PhD,${ }^{\text {b }}$ Sidney G. Shaw, DPhil, ${ }^{\mathrm{c}}$ Maria S. Fernández Alfonso, PhD, ${ }^{\mathrm{d}}$ Lennart Bodin, $\mathrm{PhD},{ }^{\mathrm{e}}$ and Domingos S. R. Souza, MD, $\mathrm{PhD}^{\mathrm{f}}$

Objective: Conventional harvesting of saphenous vein used for coronary artery bypass surgery induces a vasospasm that is overcome by high-pressure distension. Saphenous vein harvested with its cushion of perivascular tissue by a "no touch" technique does not undergo vasospasm and distension is not required, leading to an improved graft patency. The aim of this study is to investigate the effect of surgical damage and high-pressure distension on endothelial integrity and endothelial nitric oxide synthase expression and activity in saphenous vein harvested with and without perivascular tissue.

Methods: Saphenous veins from patients $(n=26)$ undergoing coronary artery bypass surgery were prepared with and without perivascular tissue. We analyzed the effect of $300 \mathrm{~mm} \mathrm{Hg}$ distension on morphology and endothelial nitric oxide synthase/nitric oxide synthase activity using a combination of immunohistochemistry, Western blot analysis, reverse transcriptase polymerase chain reaction, and enzyme assay in distended (with and without perivascular tissue) compared with nondistended (with and without perivascular tissue) segments.

Results: Distension induced substantial damage to the luminal endothelium (assessed by CD31 staining) and vessel wall. Endothelial nitric oxide synthase expression and activity were significantly reduced by high-pressure distension and removal of, or damage to, perivascular tissue. The effect of distension was significantly less for those with perivascular tissue than for those without perivascular tissue in most cases.

Conclusion: The success of the saphenous vein used as a bypass graft is affected by surgical trauma and distension. Veins removed with minimal damage exhibit increased patency rates. We show that retention of perivascular tissue on saphenous vein prepared for coronary artery bypass surgery by the "no touch" technique protects against distension-induced damage, preserves vessel morphology, and maintains endothelial nitric oxide synthase/nitric oxide synthase activity.

The long saphenous vein (SV) is the most commonly used conduit for coronary artery bypass grafting (CABG) since its introduction in $1969 .{ }^{1}$ However, the occlusion rate of this vessel is high, with $15 \%$ to $30 \%$ of grafts failing during the first year and more than $50 \%$ of patients requiring

From the Departments of Clinical Biochemistry ${ }^{\mathrm{a}}$ and Biochemistry, ${ }^{\mathrm{b}}$ Royal Free and University College Medical School, Royal Free Campus, Pond Street, London, United Kingdom; Vasoactive Peptide Group, ${ }^{c}$ University of Bern, Bern, Switzerland; Instituto Pluridisciplinar, ${ }^{\mathrm{d}}$ Universidad Complutense, Madrid, Spain; and Departments of Statistics ${ }^{\mathrm{e}}$ and Thoracic and Cardiovascular Surgery, ${ }^{\mathrm{f}}$ Örebro University Hospital, Örebro, Sweden.

This study was supported by a British Heart Foundation Project Grant to Drs Dashwood and Tsui.

Received for publication July 21, 2008; revisions received Oct 29, 2008; accepted for publication Nov 19, 2008; available ahead of print March 12, 2009.

Address for reprints: Michael R. Dashwood, PhD, Royal Free and University College Medical School, Clinical Biochemistry, University College London, Royal Free Campus, Pond Street, London NW3 2QG, United Kingdom. (E-mail: m.dashwood@medsch.ucl.ac.uk).

J Thorac Cardiovasc Surg 2009;138:334-40

$0022-5223 / \$ 36.00$

Copyright (c) 2009 by The American Association for Thoracic Surgery

doi:10.1016/j.jtcvs.2008.11.060 regrafting within 10 years. $^{2,3}$ The precise mechanisms involved in graft failure remain unclear, although surgical trauma to the SV and the effects after implantation into the arterial circulation are important. During conventional CABG surgery, the fascial canal surrounding the vein, formed predominantly by adipose tissue, ${ }^{4}$ is opened longitudinally and the vein's outermost layer, the adventitia is damaged, leading to SV vasospasm. ${ }^{5}$ High distension pressures used to overcome vasospasm and check for leaks before graft implantation ${ }^{5}$ induce substantial damage to the vein when observed at the ultrastructural level. ${ }^{6}$ Endothelial cells appear deformed, flattened, and polymorphic, and contain an abundance of cytoplasmic vesicles. In addition, exposure of subendothelial connective tissue and occasional platelet and fibrin attachment to the intima was observed. Moreover, adventitial damage was represented by a reduced number of vasa vasorum. ${ }^{6}$

In 1996 Souza $^{7}$ described a "no touch" (NT) technique of $\mathrm{CABG}$ in which the SV is harvested complete with the surrounding fascial canal. Patients receiving NT SV grafts 

Abbreviations and Acronyms
$\mathrm{CABG}=$ coronary artery bypass grafting
DIST $=$ distended
eNOS $=$ endothelial nitric oxide synthase
NDIST $=$ nondistended
NOS $=$ nitric oxide synthase
$\mathrm{NT}=$ "no touch"
PCR = polymerase chain reaction
PVT = perivascular tissue
$\mathrm{SV}=$ saphenous vein
$\mathrm{VSMC}=$ vascular smooth muscle cell

show improved early- and long-term graft patency compared with patients undergoing conventional $\mathrm{CABG}{ }^{8,9}$ Although the mechanisms underlying the advantages of the NT technique have not been fully elucidated, the need to reduce vascular damage during harvesting and the benefits of the NT technique have been recognized. ${ }^{10-14}$ Furthermore, the presence of perivascular adipose tissue might have additional benefits for the graft. First, perivascular adipose tissue of human internal thoracic arteries has been shown to release a vasodilatory factor that might reduce vasospasm of graft vessels. ${ }^{15}$ Moreover, perivascular adipose tissue reduces the sensitivity to vasoconstrictor agents and increases the responses to some vasodilatory agents depending on tangential stress. ${ }^{16}$

These findings led us to hypothesize that perivascular tissue (PVT) surrounding NT veins protects the vein against high pressures, as occurs after implantation into the arterial circulation. Therefore, the aim of this study was to investigate possible mechanisms by which the PVT affects distension-induced damage and endothelial nitric oxide synthase (eNOS) expression and activity of SVs harvested by the conventional and NT techniques from patients undergoing CABG surgery.

\section{MATERIALS AND METHODS}

\section{Saphenous Vein Harvesting and High-Pressure Distension}

The investigation conforms with the principles outlined in the Declaration of Helsinki. Under local ethics committee approval and patients' informed consent, segments of SV were harvested from 26 patients undergoing CABG at the Department of Thoracic and Cardiovascular Surgery, Örebro University Hospital, Sweden (3 female, age 40-69 years; 23 male, age 4379 years). All patients were hypertensive and receiving antihypertensives, statins, and aspirin. From each patient, 1 segment of the SV was harvested conventionally, where the vessel was stripped of its cushion of PVT and distended with saline at a pressure of $300 \mathrm{~mm} \mathrm{Hg}$ (measured on a manometer) for 1 minute (-PVT/DIST). Another segment was also stripped of surrounding tissue, but not distended (-PVT/NDIST). NT vein segments were prepared atraumatically. The SV was removed complete with its cushion of perivascular tissue, and these segments were not distended (+PVT/NDIST; for description of original technique, refer to Vasilakis and colleagues ${ }^{6}$ and $\mathrm{Souza}^{7}$ ). An additional group was included for whom the SV was re- moved with its surrounding tissue and distended at $300 \mathrm{~mm} \mathrm{Hg}$ for 1 minute (+PVT/DIST). Samples were then prepared for appropriate processing.

\section{Histology}

Vein segments from 5 patients were formalin fixed and embedded in paraffin. Transverse $4-\mu \mathrm{m}$ sections from each of the 4 vein samples (-PVT/DIST, - PVT/NDIST, + PVT/DIST, + PVT/NDIST) were cut, sequentially mounted onto microscope slides, and stored at room temperature until ready for processing. Sections were dewaxed, hydrated, and transferred into distilled water. Standard elastic van Gieson staining was performed on slides containing 2 sections of each of the 4 vein segments.

\section{Measurement of Medial Thickness}

Medial thickness was measured at 4 opposite sites of each elastic van Gieson-stained vein section (-PVT/DIST, -PVT/NDIST, +PVT/ DIST, + PVT/NDIST) on 2 sections per slide from 5 patients. Measurements were taken from the internal to the external elastic lamina at $\times 40$ magnification (Figure 1). Distance was calculated by converting the number of pixels to micrometers using a stage micrometer on captured images.

\section{Cellular Localization of CD31 and eNOS by Immunohistochemistry}

For immunohistochemistry, antigens were unmasked by microwaving the sections in $10 \mathrm{mmol} / \mathrm{L}$ sodium citrate buffer for 5 minutes, and standard immunohistochemistry was performed as described previously using the avidin-biotin complex alkaline phosphatase method (Vector Laboratories, Peterborough, UK). ${ }^{17} \mathrm{CD} 31$ antibody was used for determination of endothelial integrity, and nerves were identified using NF200 (Dako Ltd, Glostrup, Denmark). eNOS was identified using a polyclonal anti-eNOS antibody (Santa Cruz Biotechnology, Autogen Bioclear Ltd, Calne, UK). Sections were lightly counterstained with Mayer's hematoxylin, examined by microscope, and photographed digitally, and images were stored via a KS300 imaging system (Imaging Associates, Bicester, UK).

\section{Western Blotting for CD31 and eNOS}

Segments harvested from another group of 8 patients were frozen in liquid nitrogen at surgery (within 10 minutes of removal) and stored at $-70^{\circ} \mathrm{C}$ until use. Western blots were prepared as described previously, ${ }^{17}$ where rabbit anti-eNOS (Santa Cruz Biotechnology) and monoclonal anti-CD31 (Dako Ltd) antibodies were used. Protein concentration was determined by the Bradford assay, and resultant antigen-antibody complexes were detected by incubation with avidin-biotin complex reagent (Vector) using the enhanced chemiluminescence substrate kit (Amersham Biosciences, Buckinghamshire, UK). Films were analyzed by scanning densitometry on an Ultroscan XL (LKB Wallac, Cambridge, UK) with correction of densitometric units according to the $\mathrm{B}$ actin signal, as a surrogate for cell number. eNOS protein in the adventitia was also examined by carefully dissecting this layer in the laboratory from additional NT vein segments from 5 patients and comparing adventitial/vein eNOS protein levels.

\section{Determination of eNOS mRNA Expression}

Real-time quantitative polymerase chain reaction (PCR) was used as previously described ${ }^{18}$ on RNA isolated from vein segments from 9 patients. Each sample was treated with DNAase (1 U/ $\mu \mathrm{g}$ RNA) and RQ1 RNAasefree DNAase (Promega, Wis), and then reverse transcribed into cDNA using random hexamer primers (Roche, Mannheim, Germany) and Moloney murine leukemia virus reverse transcriptase (Life Technologies Inc, Paris, France). Real-time quantitative PCR was performed using the ABI Prism 7700 Sequence Detection System (Perkin-Elmer Applied Biosystems, Foster City, Calif). 18S mRNA standard (Applied Biosystems) was used as the endogenous control. Human eNOS was amplified using the following 


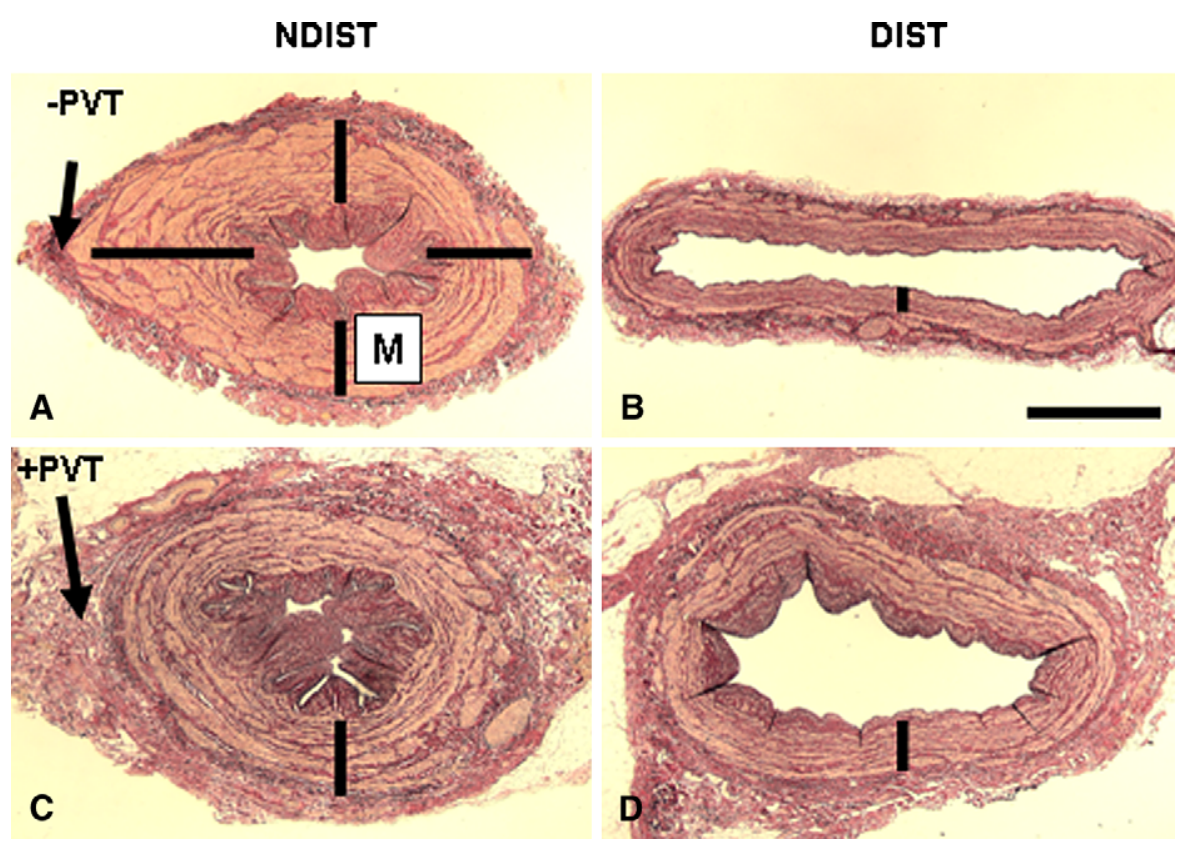

FIGURE 1. Transverse elastic van Gieson-stained SV sections comparing NDIST PVT removed (-PVT, A), intact (+PVT, C), and DIST segments with (D) and without PVT (B). The bars indicate points of media measurement. The lumen of NDIST segments was thrown into folds. Scale bar $=1 \mathrm{~mm}$. See tables for quantitative data and statistical analysis. M, Media; DIST, distended; NDIST, nondistended; PVT, perivascular tissue.

primers: forward primer 5'GAG ATG TCC GGC CCC TAC A 3' and reverse primer 5'CCC AAA CTC TCA CCC AAC TCA 3'. The 5'end FAM-labeled Taqman probe for eNOS was TCC CCT CGG CCG GAA CAG C 3'. eNOS expression was normalized to the endogenous control, $18 \mathrm{~S}$ mRNA, and the amount of eNOS mRNA in each sample expressed relative to that in the control from each patient.

\section{Determination of eNOS Activity by the Citrulline Assay}

Tissue lysates were prepared from approximately $5-\mathrm{mm}$ lengths of vein from 6 patients as described above. Total nitric oxide synthase (NOS) activity was determined by the conversion of $\left[{ }^{14} \mathrm{C}\right]$-arginine to $\left[{ }^{14} \mathrm{C}\right]$-citrulline using a NOS activity assay kit (Calbiochem, Nottingham, UK) and expressed in femtomole/minutes/milligram of protein, determined by the bicinchonic acid protein assay (Pierce, Ill). ${ }^{17}$

\section{Statistical Analyses}

Data are expressed as mean and standard deviation (Table 1). Differences between the samples collected with the different techniques (PVT and distension) were analyzed in mixed model analyses where the correlation between samples taken from the same patient could be taken into account. The technical specification of the analysis was a correlation structure with compound symmetry, and the degrees of freedom were given by the Satterthwaite method. Two specific analyses were performed. The first concerned the conventional technique (-PVT/DIST) versus the NT technique (+PVT/NDIST). In the second analysis, the 2 factors that distinguish the NT technique from the conventional technique were in focus, that is, PVT ( - or + ) and DIST (yes or no), and the interaction of these 2 factors. Statistical analysis was performed using SAS software, version 9.1.3 (SAS Institute Inc, Cary, NC).

\section{RESULTS \\ General Vessel Morphology}

The lumen of nondistended SV segments, with removed (-PVT/NDIST; Figure 1, A) or intact perivascular tissue (+PVT/NDIST; Figure 1, C), was barely visible because the intima was thrown into folds. High-pressure distension had a marked effect on morphology, as seen in the transverse plane. The intimal folds of distended segments were absent or considerably reduced in both -PVT/DIST (Figure 1, B) and + PVT/DIST (Figure $1, D$ ) veins. The mean value for the conventional method is different from NT $(P=.022$,

TABLE 1. Mean values and standard deviations for five effect measures

\begin{tabular}{|c|c|c|c|c|c|}
\hline Measure & PVT/DIST (conventional) & -PVT/NDIST & + PVT/DIST & + PVT/NDIST $($ NT) & $\begin{array}{c}P \text { value for } \\
\text { conventional versus NT }\end{array}$ \\
\hline Wall thickness $(\mathrm{n}=5)$ & $278.8(57.6)$ & $655.4(153.9)$ & $439.2(156.8)$ & $673.2(272.0)$ & .022 \\
\hline CD31 Western blots $(n=5)$ & $4.66(2.51)$ & $7.50(2.47)$ & $7.54(2.17)$ & $8.38(2.52)$ & .0009 \\
\hline Western blot for eNOS $(n=8)$ & $2.65(0.74)$ & $4.25(2.27)$ & $12.98(4.59)$ & $13.30(3.93)$ & $<.0001$ \\
\hline Citrulline assay $(n=6)$ & $0.45(0.33)$ & $1.40(0.89)$ & $2.85(0.95)$ & $3.48(0.62)$ & $<.0001$ \\
\hline eNOS mRNA $\left(\Delta \mathrm{C}_{\mathrm{T}}\right)(\mathrm{n}=9)$ & $6.68(3.82)$ & $8.16(4.47)$ & $9.70(3.92)$ & $7.93(2.38)$ & .40 \\
\hline
\end{tabular}

$P V T$, Perivascular tissue; DIST, distended; NDIST, nondistended. Statistical significance ( $P$ values) for the difference between conventional and NT is shown. 
TABLE 2. Statistical significance ( $P$ values) for differences in perivascular tissue, distension, and their interaction

\begin{tabular}{lccc}
\hline \multicolumn{1}{c}{ Measure } & $\begin{array}{c}\text { PVT }( \pm) \\
\boldsymbol{P} \text { value }^{\mathbf{a}}\end{array}$ & $\begin{array}{c}\text { DIST (yes/no) } \\
\boldsymbol{P} \text { value }\end{array}$ & $\begin{array}{c}\text { Interaction } \\
\boldsymbol{P} \text { value }\end{array}$ \\
\hline Wall thickness $(\mathrm{n}=5)$ & .13 & $<.0001$ & NS \\
CD31 Western blots $(\mathrm{n}=5)$ & .0001 & .0001 & .01 \\
Western blot for eNOS $(\mathrm{n}=8)$ & $<.0001$ & .27 & NS \\
Citrulline assay $(\mathrm{n}=6)$ & $<.0001$ & .009 & NS \\
eNOS mRNA $\left(\Delta \mathrm{C}_{\mathrm{T}}\right)(\mathrm{n}=9)$ & .29 & .89 & NS \\
\hline
\end{tabular}

$P V T$, Perivascular tissue; DIST, distended; $e N O S$, endothelial nitric oxide synthase; $N S$, not significant. ${ }^{a} P$ value from a mixed model analysis for test of PVT $( \pm)$, DIST (yes/no), and the interaction PVT*DIST. ${ }^{b}$ If interaction is not significant, results are those with no interaction factor included in the model.

Table 1), and Table 2 shows that the distension is the significant factor $(P<.0001)$ and not the PVT factor $(P=.13)$. It is, however, also seen that distension is more harmful to -PVT than to +PVT (difference due to distension is -376.6 for -PVT, -234 for + PVT), although not quite reaching statistical significance.

\section{Endothelial Integrity Determined by CD31 and eNOS Immunostaining}

The effect of high-pressure distension on the luminal endothelium, determined by CD31 staining, was observed at high magnification only in the absence of PVT. In -PVT/ DIST veins, there were large regions of endothelial denudation with only few remaining endothelial cells (Figure 2). However, in +PVT veins, endothelial cells formed an almost continuous lining of the intimal layer (Figure 2). This was also observed in -PVT/NDIST vein segments (Figure 2). Western blot analysis showed that CD31 protein was significantly lower in the conventional group (-PVT/DIST) versus the NT group (Figure 3, Table 1, $P=.0009$ ). A significant interaction between the PVT factor and the DIST factor is seen because the difference between DIST and NDIST for -PVT is large compared with the corresponding difference for $+\mathrm{PVT}$ (Table $2, P=.01$ for interaction). Thus, distension is more harmful to -PVT (difference due to distension is -2.84) than to $+\mathrm{PVT}$ (difference due to distension -0.84). Immunostaining for eNOS in -PVT/DIST segments was absent at areas of endothelial denudation (Figure 2, B). In contrast, the endothelium of nondistended veins exhibited a continuous eNOS immunostaining both in the absence $(-\mathrm{PVT} / \mathrm{NDIST}$, Figure $2, A)$ and presence (+PVT/NDIST, Figure $2, C$ ) of PVT. Moreover, eNOS immunostaining was also unaffected by distension in + PVT/DIST segments (Figure 2,D).

\section{Adventitial Integrity and eNOS Immunostaining}

As shown in Figure 4, the adventitial layer contains a network of nourishing microvessels, the vasa vasorum, and nerves. This layer remained intact in $+\mathrm{PVT}$ vein segments and exhibited positive eNOS immunoreactivity, much of which was associated with the endothelium of the vasa vasorum and the vascular nerves (Figure 4). In addition, there was dense staining of neighboring adventitial cells, composed
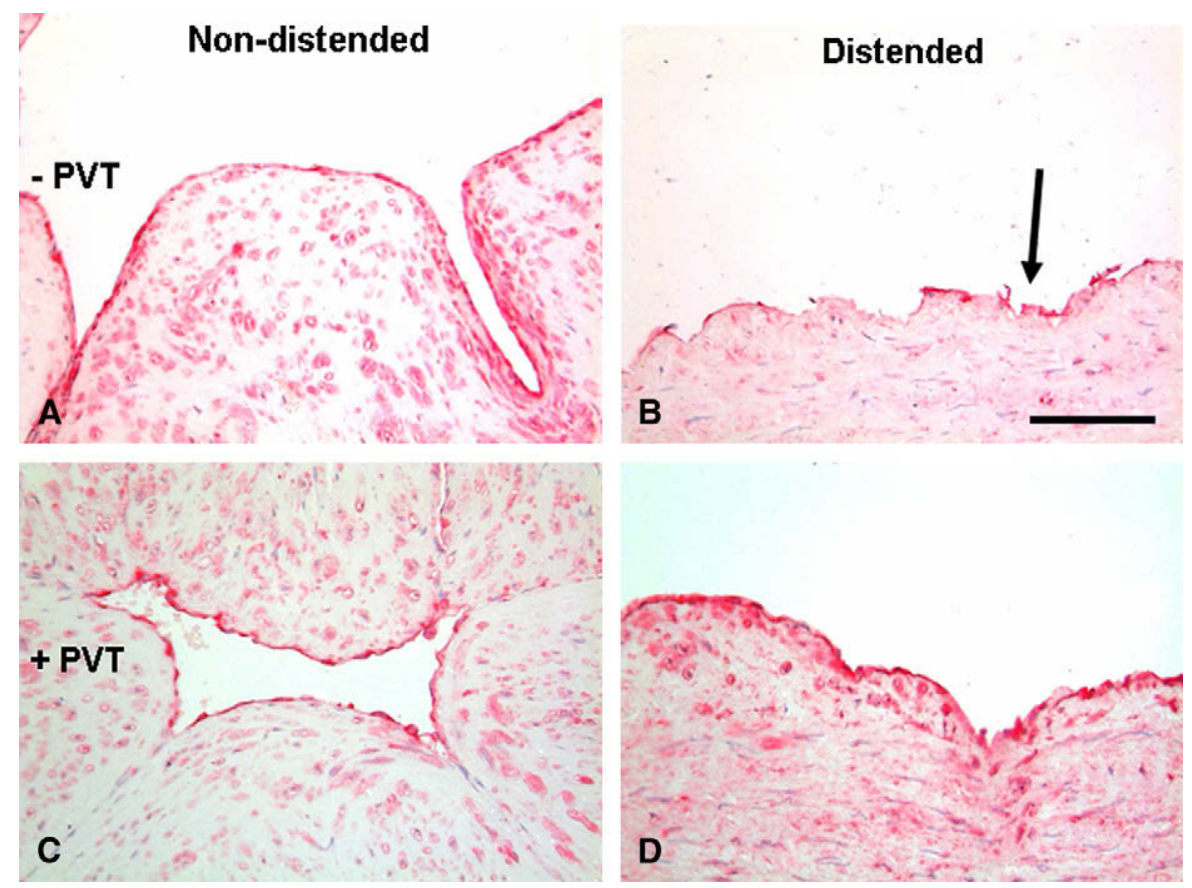

FIGURE 2. Examples of SV stained with anti-eNOS. Luminal eNOS in -PVT/DIST (conventional) vein (B) is interrupted with positive staining at regions where the endothelium is intact (arrow). Endothelial denudation is caused by high-pressure distension. In all other SV segments (A, C, and D), eNOS immunostaining is continuous. Scale bar $=0.1 \mathrm{~mm}$. $P V T$, Perivascular tissue. 


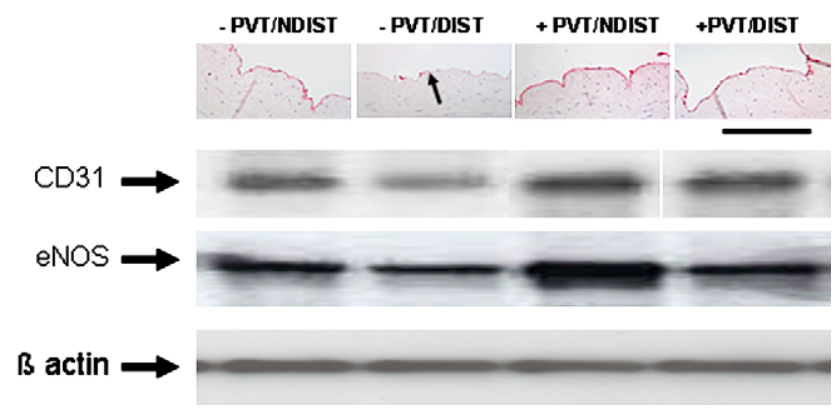

FIGURE 3. Top panels, representative photomicrographs of eNOS immunostaining of SV segments. The effect of distension on the endothelium is greater in-PVT/DIST (conventional) segments, where only few endothelial cells remain (arrow). In + PVT or NDIST segments, the endothelium remains intact (see Figure 2). Representative Western blots for CD31 (endothelial cells) and eNOS are shown with $\beta$ actin control. See tables for quantitative data and statistical analysis. eNOS, Endothelial nitric oxide synthase; $P V T$, perivascular tissue; $N D I S T$, nondistended; DIST, distended.

mainly of vascular smooth muscle cells (VSMCs,) fibroblasts, and collagen (Figure 4). These regions of eNOS immunostaining were absent in segments of -PVT/DIST and -PVT/NDIST veins, where the surrounding tissue, including the adventitia, was removed or damaged.

\section{eNOS mRNA and Protein Expression}

To quantify eNOS expression, real-time reverse transcriptase PCR was performed. Of the 3 NOS isoforms, eNOS mRNA levels were highest in the SV (our unpublished data; S. G. Shaw, DPhil, November 5, 2002). There were no significant differences between groups in cycle times relative to $18 \mathrm{~S}$ mRNA $\left(\Delta \mathrm{C}_{\mathrm{T}}\right)(-\mathrm{PVT} / \mathrm{DIST}=6.7 \pm 3.8 ;-\mathrm{PVT} /$ NDIST $=8.2 \pm 4.5 ;+\mathrm{PVT} / \mathrm{NDIST}=7.9 \pm 2.4 ;+\mathrm{PVT} /$ DIST $=9.7 \pm 3.9$ ).

Western blot analysis showed a significant difference between $-\mathrm{PVT} / \mathrm{DIST}$ and $+\mathrm{PVT} / \mathrm{NDIST}(P<.0001$, Table 1; Figure 3), and the difference is basically dependent on the PVT factor (Table $2, P<.0001$ ) and not the DIST factor (Table $2, P=.27$ ). However, the difference due to distension was higher for -PVT than for + PVT $(-1.60$ vs -0.32 , although not reaching statistical significance). Because + PVT/NDIST segments exhibited significantly higher eNOS protein levels than both -PVT/DIST and -PVT/NDIST segments, the perivascular cushion was separated from NT segments in 5 further cases. This layer expressed $34 \% \pm 5 \%$ (mean \pm standard error of the mean, $\mathrm{n}=5$ ) more eNOS protein than the SV segments from which they had been removed $(P<.05$, data not shown).

\section{NOS Activity}

NOS activity was determined using the citrulline assay. According to the higher eNOS protein expression described in the perivascular surrounding cushion, + PVT segments exhibited a higher eNOS activity than -PVT segments (Table $1, P<.0001$ ). The effect of distension on NOS activity was also significant (Table $2, P=.009$ ) and not dependent on the presence of PVT (Table 2, interaction

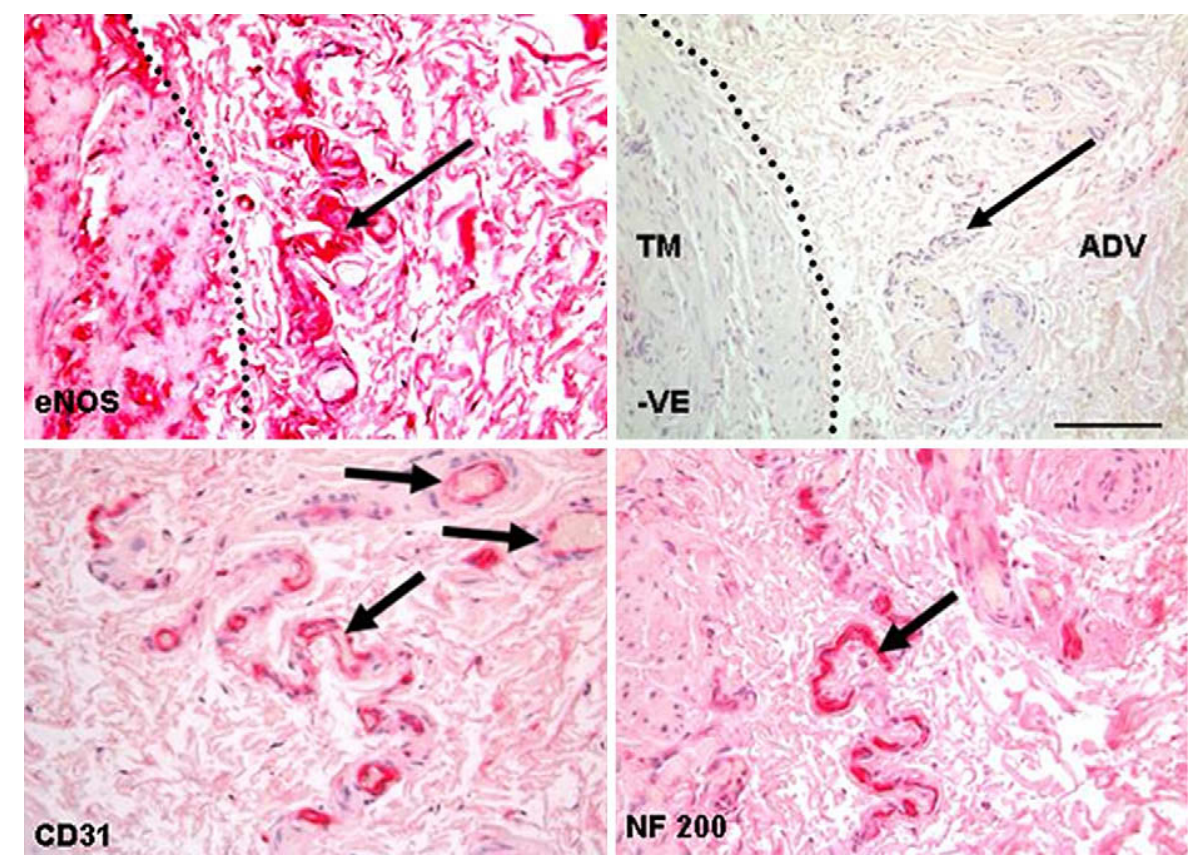

FIGURE 4. eNOS immunostaining of the vasa vasorum (CD31) and vascular nerves (NF200) within the adventitia of a + PVT/NDIST segment (arrows). The surrounding VSMCs, fibroblasts, and collagen also exhibit eNOS immunoreactivity. A negative control is shown (-VE). Dotted lines indicate the external elastic lamina separating the tunica media and adventitia . Scale bar $=0.05 \mathrm{~mm}$. $e N O S$, Endothelial nitric oxide synthase; $T M$, tunica media; $A D V$, adventitia. 
not significant). There was a significant reduction in activity in -PVT/DIST compared with -PVT/NDIST (Table 1, $P<.0001)$. However, there were no significant differences between + PVT/DIST and + PVT/NDIST segments.

\section{DISCUSSION}

In this study we show that surgical trauma caused by removal of PVT and high-pressure distension using conventional harvesting techniques damages the integrity of the endothelium and the adventitia in SVs used for CABG surgery, leading to a reduction in eNOS protein and eNOS activity. The distension-induced damage is attenuated in veins surrounded by PVT, suggesting that there is a "protective" action of the vein's surrounding cushion that may be maintained once the NT vein is placed under arterial pressure at completion of graft implantation. Also, high-pressure distension substantially alters vein morphology and affects all 3 vein layers. The luminal folds and endothelial integrity of NT vein segments is preserved, whereas endothelial denudation occurs in conventionally harvested SVs that are distended and stripped of their perivascular cushion. ${ }^{12}$ The integrity of the luminal endothelium of distended NT veins ( $+\mathrm{PVT} /$ DIST) is preserved, confirming that the PVT reduces endothelial damage caused by saline distension in these segments.

Vascular damage and high-pressure distension also correlate with a reduction in eNOS immunostaining, eNOS protein levels, and eNOS activity. The use of realtime reverse transcriptase PCR showed no effect on expression of eNOS mRNA and no significant difference between all SV segments studied (Tables 1 and 2, $P>.05$ ). Although up-regulation of immediate-early c-fos and c-myc genes occurs within 1 hour of SV harvesting, ${ }^{19}$ our results suggest that the effect on tissue eNOS protein and activity, at least in the short term, does not involve transcriptional regulation. Segments with PVT exhibited significantly higher levels of eNOS protein and activity than stripped segments and were almost unaffected by high-pressure distension. This is because a considerable proportion of the vein's eNOS is associated with the adventitia and potential nitric oxideproducing structures, such as the vasa vasorum and vascular nerves. Because the adventitia is damaged during conventional CABG, we propose that injury of this layer contributes to graft failure and that its preservation plays an important role in the success of the NT technique. ${ }^{14,20,21}$ The vasa vasorum nourishes both perivascular nerves and adipose tissue $^{22}$ and provides the media with oxygen and nutrients. ${ }^{23}$ Disruption of the vasa vasorum results in abnormal morphology of VSMCs and stiffening of the outer media, thus reducing the vessel's vasodilator capacity. ${ }^{24}$ Furthermore, occlusion or severing of these microvessels leads to medial ischaemia and subsequent neointimal hyperplasia. ${ }^{25} \mathrm{Al}-$ though the vasa vasorum of NT veins is "disconnected" at harvesting, blood supply to the vessel wall will be restored because retrograde blood flow has been observed on re- moval of vascular clamps at completion of anastomosis. ${ }^{9}$ The benefits of maintaining the graft's endogenous eNOS activity and NO production may be highly relevant for the prevention of vein graft occlusion because it has been shown that adventitial liposomal transfection of eNOS gene reduces vein graft failure ${ }^{26}$ and adenoviral eNOS transfection inhibits the migration and proliferation of VSMCs and platelet adhesion in human SV tissue. ${ }^{27}$

\section{CONCLUSIONS}

One interesting finding of this study is that preserving the external perivascular cushion of the vein reduces histologic signs of tissue damage and the effect of distension on endothelial and adventitial integrity at the time of vein harvesting. In addition to endothelial loss, placement of SV grafts into high-pressure conditions induces a number of early changes in the expression of genes stimulating VSMC proliferation ${ }^{19}$ and phosphorylation of p38-MAPK, a factor involved in graft occlusion. ${ }^{28}$ Therefore, we stress the importance of the PVT acting as a buffer and protecting the vein against arterial pressures at completion of graft implantation, with the luminal endothelium and adventitia remaining intact postoperatively. In this regard, several artificial manipulations, such as perivascular application of fibrin glue ${ }^{29}$ or placement of an external stent, ${ }^{30}$ have been demonstrated to reduce circumferential vein stretching at arterial pressures. Also, NOS levels and activity increase in the adventitia of stented grafts compared with unstented grafts. ${ }^{31}$ Moreover, the presence of perivascular adipose tissue, which modulates vascular function in several experimental models and various blood vessels, ${ }^{15,16,32-36}$ may have additional benefits on graft patency.

We thank Mats Karlsson, Alexandra Kolaric, and Laila Örtensjö for help in tissue collection and Derek Filbey for helpful discussions in planning this study. We also thank Xu Shi-Wen and David Abraham for help with Western analyses.

\section{References}

1. Favarolo RG. Saphenous vein graft in the surgical treatment of coronary artery disease: operative technique. J Thorac Cardiovasc Surg. 1969;58:178-85.

2. Mehta D, Izzat MB, Bryan AJ, Angelini GD. Towards the prevention of vein graft failure. Int J Cardiol. 1997;62(Suppl 1):S55-63.

3. TransAtlantic Inter-Society Consensus. Management of peripheral arterial disease (PAD). Eur J Vasc Endovasc Surg. 2000;19(Suppl A):S188-9.

4. Padopoulos NJ, Sherif MF, Albert EN. A fascial canal for the great saphenous vein: gross and microanatomical observations. J Anat. 1981;132:321-9.

5. Mann JM, McIntosh CL, Roberts WC. Spasm of saphenous vein used as conduits for bypass grafting. Am J Cardiol. 1987;59:1000-2.

6. Vasilakis V, Dashwood MR, Souza DSR, Loesch A. Human saphenous vein and coronary bypass surgery: scanning electron microscopy of conventional and "notouch"' grafts. Vasc Dis Prev. 2004;1:133-9.

7. Souza DRS. A new no-touch preparation technique. Scand J Thorac Cardiovasc Surg. 1996;30:41-4.

8. Souza DRS, Bomfim V, Skoglund H, Dashwood MR, Borowiec JW, Bodin L, et al. High early patency in saphenous vein graft for coronary artery bypass harvested with surrounding tissue. Ann Thorac Surg. 2001;71:797-800.

9. Souza DSR, Johansson B, Bojö L, Karlsson R, Geijer H, Filbey D, et al. Harvesting the saphenous vein with surrounding tissue for CABG provides long-term graft patency comparable to the left internal thoracic artery: results 
of a randomized longitudinal trial. J Thorac Cardiovasc Surg. 2006;132: 373-8.

10. Shuhaiber JH, Evans AN, Massad MG, Geha AS. Mechanisms and future directions for prevention of vein graft failure in coronary artery bypass surgery. Eur J Cardiothorac Surg. 2002;22:387-96.

11. Souza DS, Christofferson RH, Bomfim V, Filbey D. "No-touch" technique using saphenous vein harvested with its surrounding tissue for coronary artery bypass grafting maintains an intact endothelium. Scand Cardiovasc J. 1999;33: 323-9.

12. Tsui JCS, Souza DSR, Filbey D, Bomfim V, Dashwood MR. Preserved endothelial integrity and nitric oxide synthase in saphenous vein harvested by a "notouch", technique. Br J Surg. 2001;88:1209-15.

13. Tsui JCS, Souza DSR, Filbey D, Karlsson MG, Dashwood MR. Localization of nitric oxide synthase in saphenous vein grafts harvested with a novel "no-touch", technique: potential role of nitric oxide contribution to improved early graft patency. J Vasc Surg. 2002;35:356-62.

14. Tsui JCS, Dashwood MR. Recent strategies to reduce vein graft occlusion: a need to limit the effect of vascular damage. Eur J Vasc Endovasc Surg. 2002;23:202-8.

15. Gao Y-J, Zeng Z, Teoh K, Sharma A, Abouzhar L, Cybulsky I, et al. Perivascular adipose tissue modulates vascular function in the human internal thoracic artery. J Thorac Cardiovasc Surg. 2005;130:130-6.

16. Ford CA, Mong K, Tabrizchi R. Influence of tangential stress on mechanical responses to vasoactive agents in human saphenous vein with and without perivascular adipose tissue. Can J Cardiol. 2006;22:1209-16.

17. Dashwood MR, Savage K, Dooley A, Shi-Wen X, Abraham DJ, Souza DSR. Effect of vein graft harvesting on endothelial nitric oxide and nitric oxide production. Ann Thorac Surg. 2005;80:939-44.

18. Tsui JC, Baker DM, Shaw SG, Dashwood MR. Alterations in nitric oxide synthase isoforms in acute lower limb ischaemia and reperfusion. Angiology. 2007; 58:586-92.

19. Moggio RA, Ding J-Z, Smith CJ, Tota RR, Stemerman MB, Reed GE. Immediateearly gene expression in human saphenous veins harvested during coronary artery bypass operation. J Thorac Cardiovasc Surg. 1995;110:209-13.

20. Gutterman DD. Adventitia-dependent influences on vascular function. Am J Physiol. 1999;277:H1265-72.

21. Dashwood MR, Anand R, Souza DSR. Hypothesis: a potential role for the vasa vasorum in the maintenance of vein graft patency. Angiology. 2004;55: 385-95.

22. Corson JD, Leather RP, Balko A, Naraynsingh V, Karmody AM, Shah DM. Relationship between vasa vasorum and blood flow to vein bypass endothelial morphology. Arch Surg. 1985;120:386-8.

23. Kachlik D, Lamentschandter A, Rejmontova J, Stingl J, Vanek I. Vasa vasorum of the human great saphenous vein. Surg Radiol Anat. 2002;24:376-80.
24. Angouros D, Sokolis DP, Dosios T, Kostomitsopoulos N, Boudoulas H, Skalkeas G, et al. Effect of impaired vasa vasorum flow on the structure and mechanics of the thoracic aorta: implications for the pathogenesis of aortic dissection. Eur J Cardiothorac Surg. 2000;17:468-73.

25. Barker SG, Tilling LC, Miller GC, Beesley JE, Fleetwood G, Stavri GT, et al. The adventitia and atherogenesis: removal initiates intimal proliferation in the rabbit which regresses on generation of a "neoadventitia". Atherosclerosis. 1994;105: 131-44.

26. Kalra M, Jost CJ, Severson SR, Miller VM. Adventitial versus intimal liposomemediated ex vivo transfection of canine saphenous vein with endothelial nitric oxide synthase gene. J Vasc Surg. 2000;32:1190-200.

27. Tsukurov OI, Kwolek CJ, L'Italien GJ, Banbrahim A, Milinazzo BB, Conroy NE, et al. The response of adult human saphenous vein endothelial cells to combined pressurized pulsatile flow and cyclic strain, in vitro. Ann Vasc Surg. 2000;14: 260-7.

28. Cornelissen J, Armstrong J, Holt CM. Mechanical stretch induces phosphorylation of p38-MAPK and apoptosis in human saphenous vein. Arterioscler Thromb Vasc Biol. 2004;24:451-6.

29. Stooker W, Gök M, Sipkema P, Niessen HW, Baidoshvili A, Westerhof N, et al. Pressure-diameter relationship in the human greater saphenous vein. Ann Thorac Surg. 2003;76:1533-8.

30. McGregor E, Gosling M, Beattie DK, Ribbons DMP, Davies AH, Powell JT. Circumferential stretching of saphenous vein smooth muscle enhances vasoconstrictor responses by Rho kinase-dependent pathways. Cardiovasc Res. 2002;53: 219-26.

31. Jeremy JY, Dashwood MR, Mehta D, Izzat MB, Shukla N, Angelini GD. Nitric oxide, prostacyclin and cyclic nucleotide formation in externally stented porcine vein grafts. Atherosclerosis. 1998;141:297-305.

32. Fernandez-Alfonso M. Regulation of vascular tone: the fat connection. Hypertension. 2004;44:255-6.

33. Lohn M, Dubrovska G, Lauterbach B, Luft FC, Gollasch M, Sharma AM. Periadventitial fat releases a vascular relaxing factor. FASEB J. 2002;16: 1057-63

34. Verlohren S, Dubrovska G, Tsang SY, Essin K, Luft FC, Huang Y, et al. Visceral periadventitial adipose tissue regulates arterial tone of mesenteric arteries. Hypertension. 2004;44:271-6.

35. Galvez B, de Castro J, Herold D, Dubrovska G, Arribas S, Gonzalez MC, et al. Perivascular adipose tissue and mesenteric vascular function in spontaneously hypertensive rats. Arterioscler Thromb Vasc Biol. 2006;26: 1297-302.

36. Dashwood MR, Dooley A, Shi-Wen X, Abraham DJ, Souza DSR. Does periadventitial fat-derived nitric oxide play a role in improved saphenous vein graft patency in patients undergoing coronary artery bypass surgery? J Vasc Res. 2007;44: 175-81. 